Current Research in Dentistry 1 (1): 6-10, 2010

ISSN 1949-0119

(C) 2010 Science Publications

\title{
Age and Sequence of Permanent Canine and Premolar Teeth Eruption in 102-174 Months Old Children in Kerman Province
}

\author{
Farokhgissor Elham and Shahrzad Adhamy \\ Department of Peadiatric Dentistry, \\ Kerman University of Medical Science, Iran
}

\begin{abstract}
Problem statement: The aim of this study was to investigate the eruption time of permanent canine and premolar teeth in 8.5-14.5 years (102-174 months) old boys and girls of Kerman province. Approach: The sample for this cross-sectional study consisted of 2602, 102-174 months old (8.5-14.5 years old) children form 56 primary and guidance schools in Kerman which were scattered over in 2 districts of the city. There were 1556 of girls and 1046 of boys were chosen by simple randomization and the emergence stage of each tooth was recorded. Results: The analysis indicated significantly earlier emergence ages in girls than in boys. The eruption pattern turned out to be symmetric in both sexes and no statically significant difference was detected between the right and left side. The most common observed emergence pattern in girls was mandibular canine and maxillary first premolar followed by mandibular first premolar, maxillary second premolar, then mandibular second premolar and canine and in boys it was maxillary and mandibular first premolar, mandibular canine, maxillary second premolar, mandibular second premolar and maxillary canine Conclusion: Significantly earlier emergence ages in girls seen than in boys. The sequence of eruption differs between girls and boys for mandibular canine and first premolar. It may be concluded that the eruption timing and sequence seen in large sample of children from Kerman revealed that emergence of teeth appeared later than other ethnic group these finding are relevant for dental treatment planning, forensic evaluation and should be reconfirmed at certain interval.
\end{abstract}

Key words: Mandibular Canine, premolar teeth, tooth eruption, maxillary counterpart, canine emerged, Standard Devotion (SD), Confidence Interval (CI), ethnic group

\section{INTRODUCTION}

Adequate knowledge of timing and pattern of permanent teeth emergence is essential for diagnosis of developmental disturbance (Mugonzibwa et al., 2002) and treatment planning in (pediatric) dentistry (Leroy et al., 2003a; 2003b), anthropological use (Savara and Steen, 1978) and caries prevention programs (Garn et al., 1973). Several factors have been found to be related to the timing of the emergence of permanent teeth, for example: weight and height of children (Billewicz and McGregor, 1975; Triratana et al., 1990) economic and social status (Stewart, 1982), gender, ethnicity, environmental and secular factors (Virtanen et al., 1994).

Emergence of permanent teeth has been studied among different population and among different ethnic groups (Eskeli et al., 1999; Pahkala et al., 1991; Johannessen et al., 1989; Manji and Mwaniki, 1985; Richardson et al., 1975; Atai et al., 2007). In the literature it has been suggested that standards for tooth emergence should be derived from the population in which they are to be applied because factors related to tooth emergence of both deciduous and permanent dentition may vary.

There is little or no information about the time and sequence of the eruption of permanent teeth in Kerman. Accordingly, there is a need for the construction of reliable reference table on permanent teeth emergence in this population. The aim of this study was to investigate the eruption time of permanent canine and premolar teeth in 8.5-14.5 years (102-174 months) old children of Kerman.

\section{MATERIALS AND METHODS}

Population and sample: The sample for this crosssectional study consisted of 2602 102-174 months old (8.5-14.5 years old) children form 56 primary and guidance schools in Kerman which were scattered over in 2 districts of the city. There were 1556 of girls and 1046 of boys were chosen by simple randomization.

Corresponding Author: Farokhgissor Elham, Department of Peadiatric Dentistry, Kerman University of Medical Science, Kerman, Iran 
Clinical examination: Before starting, sessions were arranged for children and their parents to describe and discuss the study and obtain consent. Dental examinations were carried out by trained dentistexaminers. Each of the canine and premolar teeth was scored according to its clinical eruption stage. The scoring was as below:

\section{No visible tooth:}

Any visible tooth structure: Sex and age (in month) of the children were also recorded.

If any of these conditions existed, it would be excluded from the study:

- $\quad$ Tilting of first molar more than $2 \mathrm{~mm}$

- Early loss of first and second deciduas molar

- Sever crowding

For statistical analysis, SPSS and Mann-Whitney test were used and P-value of less than 0.05 was considered statistically significant.

\section{RESULTS}

Table 1and 2 shows) mean, Standard Devotion (SD), Minimum (Min), Maximum (Max) and the Confidence Interval (CI): Eruption time in boys and girls.
Table 3 shows the mean time of the eruption. The results showed that the average age at the eruption of permanent teeth in girls is significantly younger than the boys.

The average time of permanent teeth eruption between girls and boys ranged from 4-7 month. With the largest difference being seen in mandibular canine (7 months).

The eruption pattern turned out to be symmetric in both sexes and no statically significant difference was detected between the right and left side. The result of this study also showed that the mandibular teeth have an earlier eruption time than maxillary counterpart in both girls and boys with the exception of the first and second premolar. There was no significant difference in mean age of permanent teeth eruption in left and right side of jaws in both groups. Our result revealed that the average age at eruption time of mandibular canine in girls was younger than boys and also revealed earlier eruption of comparable teeth in females as against males. In both groups the maxillary canine appeared after the second premolar. Emergence of mandibular canine in female was about 11, 9 years and first premolar appeared at the same time as the manidbular canine.

The emergence of the first premolar of both jaws was of the same time in 12.6 year that is later than girls.

Table 1: Mean, Standard Devotion (SD), Minimum (Min), Maximum (Max) and the Confidence Interval (CI): Eruption time in boys

\begin{tabular}{lllllll}
\hline The sequence of tooth eruption & number & mean & SD & min & Max & CI \\
\hline Max. right second premolar & 616 & $151 / 8$ & 14 & 38 & 204 & $155 / 5-157 / 6$ \\
Max. left second premolar & 626 & $151 / 7$ & $16 / 7$ & 95 & 201 & $150 / 3-153$ \\
Mand. right second premolar & 520 & $153 / 4$ & $16 / 5$ & 95 & 201 & $152-154 / 8$ \\
Mand. left second premolar & 516 & $153 / 1$ & 17 & 95 & 201 & $151 / 6-154 / 6$ \\
Max. right first premolar & 720 & $149 / 1$ & $17 / 7$ & 95 & 201 & $147 / 8-150 / 4$ \\
Max. left first premolar & 723 & $149 / 2$ & $17 / 5$ & 95 & 201 & $147 / 9-150 / 5$ \\
Mand. right first premolar & 678 & $150 / 3$ & 17 & 95 & 201 & $149-151 / 6$ \\
Mand. left first premolar & 679 & $150 / 2$ & $17 / 2$ & 95 & 201 & $148 / 8-151 / 5$ \\
ax. right canine & 471 & $154 / 7$ & $16 / 7$ & 95 & 201 & $153 / 2-156 / / 2$ \\
Max. left canine & 471 & $154 / 7$ & $16 / 7$ & 95 & 190 & $153 / 2-156 / / 2$ \\
Mand. right & & & & & \\
canine & 793 & $148 / 8$ & $17 / 5$ & 95 & 201 & $147-149 / 3$ \\
Mand. left canine & 793 & $148 / 8$ & $17 / 5$ & 95 & 201 & $147-149 / 3$ \\
\hline
\end{tabular}

Table 2: Mean, Standard Devotion (SD), Minimum (Min), Maximum (Max) and the Confidence Interval (CI): Eruption time in girls

\begin{tabular}{|c|c|c|c|c|c|c|}
\hline The sequence of tooth eruption & number & mean & SD & $\min$ & Max & CI \\
\hline Max. right second premolar & 610 & $156 / 5$ & 14 & 38 & 204 & $155 / 5-157 / 6$ \\
\hline Max. left second premolar & 610 & 667 & $14 / 2$ & 38 & 204 & $155 / 4-157 / 7$ \\
\hline Mand. right second premolar & 558 & $157 / 8$ & $13 / 7$ & 38 & 204 & $156 / 6-159$ \\
\hline Mand. left second premolar & 561 & $157 / 6$ & $13 / 8$ & 38 & 204 & $156 / 5-158 / 8$ \\
\hline Max. right first premolar & 667 & $154 / 7$ & $15 / 1$ & 38 & 204 & $153 / 5-155 / 8$ \\
\hline Max. left first premolar & 667 & $154 / 7$ & $15 / 2$ & 38 & 204 & $153 / 4-155 / 7$ \\
\hline Mand. right first premolar & 637 & $155 / 6$ & 17 & 38 & 204 & $154 / 5-156 / 8$ \\
\hline Mand. left first premolar & 632 & $155 / 9$ & $17 / 2$ & 38 & 204 & 154/8-157 \\
\hline ax. right canine & 500 & $159 / 6$ & $16 / 7$ & 38 & 204 & 158-160/7 \\
\hline Max. left canine & 509 & 159/7 & $16 / 7$ & 38 & 204 & 158/6-160/7 \\
\hline \multicolumn{7}{|l|}{ Mand. right } \\
\hline canine & 661 & $154 / 5$ & $17 / 5$ & 38 & 204 & 153/4-155/7 \\
\hline Mand. left canine & 672 & $154 / 2$ & $17 / 5$ & 38 & 204 & $153 / 2-155 / 2$ \\
\hline
\end{tabular}


Current Research in Dentistry 1 (1): 6-10, 2010

Table3: The mean $( \pm \mathrm{SD})$ time of tooth eruption

\begin{tabular}{llll}
\hline & Girls & Boys & \\
Tooth & Eruption time & Eruption time p-value \\
\hline Max. right second premolar & $148.6 \pm 18.0$ & $152.8 \pm 16.3$ & \\
Max. left second premolar & $148.8 \pm 17.7$ & $152.7 \pm 16.4$ & \\
Mand. right second premolar & $149.5 \pm 17.4$ & $154.4 \pm 15.6$ & \\
Mand. left second premolar & $149.1 \pm 17.6$ & $154 \pm 16.00$ & \\
Max. right first premolar & $143 \pm 20.00$ & $149.5 \pm 17.6$ & \\
Max. left first premolar & $142.7 \pm 20.0$ & $149.1 \pm 18.0 \quad<0.0001$ \\
Mand. right first premolar & $144.7 \pm 19.0$ & $149.5 \pm 17.7$ & \\
Mand. left first premolar & $143.9 \pm 19.5$ & $149.5 \pm 18.0$ & \\
Max. right canine & $149.2 \pm 17.2$ & $154.8 \pm 15.1$ & \\
Max. left canine & $149.2 \pm 17.2$ & $155.2 \pm 14.7$ & \\
Mand. right canine & $143.3 \pm 19.7$ & $150.3 \pm 17.1$ & \\
Mand. left canine & $143.2 \pm 19.7$ & $150.3 \pm 17.1$ & \\
\hline
\end{tabular}

In females eruption time for mandibular first premolar was at 12 years and for maxillary second premolars was at 12.9 years. The mandibular first premolar erupted at 12 years the mandibular and maxillary canine emerged at 12.5 years in males the emergence of mandibular canine was at 12.6 years. That is earlier in female by about 1 year. At least the emergence of the maxillary second premolar in males was at 12.11 years and also the maxillary canine emerged at approximately at the same time. Both the maxillary and mandibular canine and premolar in female appeared earlier than in males.

The emergence of the permanent teeth in Kerman children is a little delayed compared to most of the other populations. The most common observed emergence pattern in girls was mandibular canine and maxillary first premolar followed by mandibular first premolar, maxillary second premolar, then maxillary mandibular second premolar and canine and in boys it was maxillary and mandibular first premolar, mandibular canine, maxillary second premolar, mandibular second premolar and maxillary canine.

The range of variation in eruption time differed for differing permanent teeth and between girls and boys. In girls the minimum range of variation in eruption (17.2 months) was seen in maxillary canine. The maximum range of variation in girls (20 months) was seen for the maxillary first premolar. In boys the minimum range of variation of eruption (14.7 months) was seen in the maxillary canine and the maximum range of variation in boys was seen in mandibular first premolar (18 months).

\section{DISSCUSION}

Cross sectional data on permanent teeth eruption (canine and premolar) were collected from 2602 subject of primary and junior school in Kerman Province of Iran.
Since the Kerman is the largest province in Iran country and survey the timing and sequence of teeth eruption provide an important foundation to understanding the biology and culture of past and present population this information is also of clinical significance in child health planning, diagnosis and treatment planning (Hussin et al., 2007).

The results showed that the average age at the eruption of permanent teeth in girls is significantly younger than in boys.

The average time of permanent teeth eruption between girls and boys ranged from 4-7 month. With the largest difference being seen in mandibular canine (7 months).

These results are in parallel with those described elsewhere in the literature.

Stewart (1982) reported difference in the eruption time between genders to be a maximum of 2-10 months and Hagg and Taranger (1985); Hurme (1949) and Kim et al. (2003) reported that average age at eruption among girl was distinctively earlier than in boys. This survey clearly confirm to previous findings.

The result of this study also showed that the mandibular teeth have an earlier eruption time than maxillary teeth in both girls and boys with the exception of the first and second premolar. That is in parallel with the other studies in literature Blankenstein and Cleaton (1990); Kochhar and Richardson (1998) and Mugonzibwa et al. (2002).

It is postulated that there are numerous factors which influence the development and eruption of teeth including: endocrine, genetic, nutrition and ethnics. The emergence of permanent maxillary first and second premolar in Kerman population was earlier than the mandibular counterpart. Similar sequence of eruption seen in other studies. Nizam et al. (2003) reported that all mandibular teeth with the exception of first and second premolar in both males and females, tended to erupt earlier than the maxillary counterpart, Kochhar and Richardson (1998) and Friedrich et al. (2007) also showed similar results.

Our result revealed that the average age at eruption time of mandibular canine in girls was younger than boys.

This study confirms earlier eruption of comparable teeth in females as against males.

Early eruption is generally a conflict of earlier maturation in the females (Nizam et al., 2003). But Earlier eruption in boys reported by Wedi et al. (2005).

There are no substantial differences in the sequence and timing of permanent teeth eruption compared with other studies such as Japan (Hoffding et al., 1984) America (Pahkala et al., 1991) Finland (Moslemi, 2004) Denmark (Hughes et al., 2007), Tehran 
(Mahmoodian, 1998) knowledge about eruption time for canine and premolar is critical for dental treatment planning specially in orthodontic in cases of a space deficit in the canine region.

There was no significant difference in mean age of permanent teeth eruption in left and right side of jaws in both groups.

That is agree with Kochhar and Richardson (1998) and Hughes et al. (2007).

In both groups the maxillary canine appeared after the second premolar. Emergence of mandibular canine in female was about 11, 9 years and first premolar appeared at the same time as the mandibular canine.

The emergence of the first premolar of both jaws was of the same time in 12.6 year that is later than girls.

In females eruption time for mandibular first premolar was at 12 years and for maxillary second premolars was at 12.9 years. The mandibular first premolar erupted at 12 years the mandibular and maxillary canine emerged at 12.5 years in males the emergence of mandibular canine was at 12.6 years. That is earlier in female by about 1 year.

At least the emergence of the maxillary second premolar in males was at 12.11 years and also the maxillary canine emerged at approximately at the same time. Both the maxillary and mandibular canine and premolar in female appeared earlier than in males.

The emergence of the permanent teeth in Kerman children is a little delayed compared to most of the other populations.

Our study revealed that the mean age of emergence of teeth is earlier than maxillary counterpart in both grills and boys. But maxillary first and second premolar erupted earlier than mandibular counterpart. The sequence of eruption in this study is in accordance with previous study (Hurme, 1949; Kim et al., 2003; Blankenstein and Cleaton, 1990; Kochhar and Richardson, 1998; Mahmoodian, 1998) also found the same pattern for premolar teeth eruption with exception mandibular first premolar, which erupted earlirt than mandibular canine. But our result is in contrast with (Moslemi, 2004; Mahmoodian, 1998).

Similar sequence in eruption seen, at least comparison of our result with other states in America (Wedi et al., 2005) Finland (Hoffding et al., 1984) Tanzania (Mugonzibwa et al., 2002) revealed that eruption time in Kermanian children is later.

Factors affecting the time and sequence of eruption such as genetic over weight (Billewicz and McGregor, 1975; Triratana et al., 1990; Stewart, 1982) fluorides and caries environmental ethnicity socio economic and secular factor (Virtanen et al., 1994).
Ethnic origin has been proven by many investigators to have influence on the timing of teeth eruption.

It is said to exert more influence that other variable such as the socio economic status or nutrition. Socio economic conditions may play a major role in general stomatic growth but their effect on dental development is considered to be insignificant (Hussin et al., 2007)

\section{CONCLUSION}

It may be concluded that the eruption timing and sequence seen in large sample of children from Kerman revealed that emergence of teeth appeared later than other ethnic group these finding are relevant for dental treatment planning, forensic evaluation.

\section{REFERENCES}

Atai, Z., M. Ansari and N. Torabi, 2007. Efficacy of olive leaf extract in the treatment of minor oral aphthous ulcers. Am. J. Inf. Dis., 3: 24-26. DOI: 10.3844/ajidsp.2007.24.26

Billewicz, W.Z. and I.A. McGregor, 1975. Eruption of permanent teeth in West African (Gambian) children in relation to age, sex and physique. Ann. Hum. Biol., 2: 17-28. $\quad$ DOI: 10.1080/03014467500000661

Blankenstein, R. and P.E.J. Cleaton, 1990. The onest of eruption of permanent teeth eruption amongst South Africa Indian children. Am. Hum. Biol., 17: 515-521. DOI: 10.1080/03014469000001282

Eskeli, R., M.T. Laine-Alava, H. Hausen and R. Pahkala, 1999. Standards of permanent tooth emergence in finish children. Angle Orthod., 69: 529-533. PMID: 10593443

Friedrich, R.E., N. Kamalwand, S.W. Jurgen and H.A. Scheuer, 2007. Eruption times of permanent teeth in male children and adolescents of Tehran (Iran). Arch. Kriminol., 219: 145-168. PMID: 17612333

Garn, S.M., S.T. Sandusky, J.M. Nagy and F.L. Trowbridge, 1973. Negro-Caucasoid differences in permanent tooth emergence at a constant income level. Arch. Oral. Biol., 18: 609-615. DOI: 10.1016/00039969(73)90099-X

Hagg, U. and J. Taranger, 1985. Dental development, Dental age and tooth counts. Angle Orthod., 55: 93-107. PMID: 3860029

Hoffding, J., M. Maeda, K. Yamaguchi, H. Tsuji and S. Yoshida, 1984. Emergence of permanent teeth and onset of dental stage in Japanese children. Comm. Dent Oral. Epidemiol., 1: 55-58. DOI: 10.1111/j.1600-0528.1984.tb01411.x 
Hughes, T.E., M.R. Bockmann, K. Seow T. Gotjamanos and N. Gully et al., 2007. Strong genetic control of emergence of human primary incisors. J. Dent. Res., 86: 1160-1165. DOI: 10.1177/154405910708601204

Hurme, V., 1949. Ranges of normalcy in the eruption of permanent teeth. J. Dent. Child, 4: 161-165.

Hussin, A.S., N. Mokhtar, L. Naing, J.A. Taylor and Z. Mahmood, 2007. The timing and sequence of emergence of permanent teeth in Malay school children in Kota Bharu, Malaysia. Arch. Orofacial Sci., $\quad 2$ : 36-40. http://www.dental.usm.my/ver2/images/stories/AO S/Vol_2/3640_akbar.pdf

Johannessen, A.C., K. Bjorvatn and D. Myklebust, 1989. Oral health in children attending churchaffilicted schools in Northern Cameroon: Tooth development and dental caries. Odont. Trop., 12: 67-68.

Kim, R., J. Christiansen and M.E.C. Christiansen, 2003. Time and duration of eruption of first and second permanent molars. Commun. Dent. Oral Epidemiol., 31: 344-345. DOI: 10.1034/j.16000528.2003.00016.x

Kochhar, R. and A. Richardson, 1998. The chronology and sequence of eruption of human permanent teeth in Northern Ireland. Int. J. Paediatre, 8: 243-252. DOI: 10.1046/j.1365-263x.1998.00092.x

Leroy, R., K. Bogaerts, E. Lesaffre and D. Declerck, 2003a. The effect of fluorides and caries in primary teeth on permanent tooth emergence. Commun. Dent. Oral Epidemiol., 31: 463-470. DOI: $10.1046 /$ j.1600-0528.2003.00116.x

Leroy, R., K. Bogaerts, E. Lesaffre and D. Declerck, 2003b. The emergence of permanent teeth in Flemish children. Commun. Dent Oral Epidemiol., 31: 30-39. DOI: 10.1034/j.16000528.2003.00023.x

Mahmoodian, J., 1998. Evaluation age and sequence of permanent canine and premolar teeth eruption in 814 years old children in Isfahan city. Dent. J. Med. Tehran Univ., 11: 21-32.

Manji, F. and D. Mwaniki, 1985. Estimation of median age of eruption of permanent teeth in Kenyan children. East African Med. J., 62: 252-259. PMID: 4042932
Moslemi, M., 2004. An epidemiological survey of the time and sequence of eruption of permanent teeth in 4-15-year-olds in Tehran, Iran. Int. J. Pediatr. Dent., 14: 432-438. DOI: 10.1111/j.1365263X.2004.00586.X

Mugonzibwa, E.A., A.M. Kuijpers- Jagtman, M.T. LaineAlava, M.A. Van't Hof, 2002. Emergence of permanent teeth in Tanzanian children. Comm. Dent. Oral Epidemiol., 30: 455-462. DOI: 10.1034/j.1600-0528.2002.00020.x

Nizam, A., L. Naing and N. Mokhtar, 2003. Age and sequence of eruption of permanent teeth in Kelantan, north-eastern Malaysia. Clin. Oral Invesitg., 7: 222-225. DOI: 10.1007/s00784-0030228-1

Pahkala, R., A. Pahkala and T. Laine, 1991. Eruption pattern of permanent teeth in a rural community in northeastern Finland. Acta Odont. Scand., 49: 341-349. PMID: 1776401

Richardson, A., A. Akpata, J. Ana and R. Franklin, 1975. Comparisons of tooth eruption ages in European and West African children. Trans. Eur. Orthod. Soc., 1: 161-167. PMID: 1072153

Savara, B.S. and J.C. Steen, 1978. Timing and sequence of eruption of permanent teeth in a longitudinal sample of children from Oregon. J. Am. Dent. Assoc., 99: 209-214. PMID: 277593

Stewart, R.E., 1982. Pediatric Dentistry: Scientific Foundations and Clinical Practice. Mosby, St Louis, MO., CV., ISBN: 0801648041 , pp: 1027.

Triratana, T., D. Hemindra and C. Kiatiparjuk, 1990. Eruption of permanent teeth in malnourished children. J. Dent. Assoc. Thai, 40: 100-108. PMID: 2127420

Virtanen, J., R.S. Bloigu and M.A. Larmas, 1994. Timing of eruption of permanent teeth: Standard Finnish patient documents. Comm. Dent Oral Epidemiol., 22: 286-288. PMID: 7813177

Wedi, J.S., S. Danias, R. Schmelzle and R.E. Fridrich, 2005. Eruption times of permanent teeth in children and adolescencts in Athens (Greece). Clin. Oral Invest., 9: 131-134. DOI: 10.1007/s00784-004-0295-y 